\title{
Pembuatan dan Karakterisasi Bonded Magnet Komposit Berbasis Polimer
}

\author{
Deswita, ${ }^{*}$ Sudirman, dan Indra Gunawan \\ Pusat Penelitian Bahan Industri Nuklir (PTBIN) - BATAN \\ Kawasan Puspiptek Serpong, Tangerang Selatan 15310
}

\begin{abstract}
Intisari
Pembuatan magnet komposit berbasis polimer dengan filler $\mathrm{SrFe}_{12} \mathrm{O}_{19}$ telah dilakukan. Proses pembuatan dilakukan dengan cara mencampur serbuk $\mathrm{SrFe}_{12} \mathrm{O}_{19}(\mathrm{SrM})$ dengan polimer epoksi dan polimer poliester dengan perbandingan (dalam fraksi volume) 30, 40, 50 dan 60. Densitas sampel diukur dengan metoda Pikno-meter, sedangkan uji sifat mekanik dengan peralan standar ASTM 412 dan ISO R868. Mikrostruktur dan sifat kemagnetan sampel SrM sebagai filler diukur dengan teknik difraksi sinar-x dan Vibrating Sample Magnetometer. Hasil pengujian menunjukkan bahwa magnet komposit SrM-epoksi dengan 50\% kadar SrM memiliki densitas paling tinggi, sekitar 3,3 gr/ml. Kekuatan tarik tertinggi diperoleh sekitar $297,23 \mathrm{~kg} / \mathrm{cm}^{2}$ dari magnet komposit SrM-epoksi dengan 30\% kadar SrM. Koersivitas $\left(\mathrm{H}_{c}\right)$ dan remanensi tertinggi diperoleh dengan $\mathrm{H}_{c}=0,15 \mathrm{kOe}$ dan $\mathrm{B}_{r}=1,9$ kGauss dari komposit SrM-poliester dengan 50\% kadar SrM. Dari penelitian ini dapat disimpulkan bahwa bahan komposit SrM-epoksi memiliki sifat mekanik lebih tinggi dari pada sifat mekanik bahan komposit SrM-poliester. Ini menunjukkan bahwa polimer epoksi pada bahan magnet komposit yang berperan sebagai binder memiliki sifat yang lebih baik bila dibandingkan dengan polimer poliester untuk berbagai kadar filler SrM. Namun sebaliknya, sifat kemagnetan dari bahan magnet komposit SrM-poliester lebih baik dari pada bahan SrM-epoksi.
\end{abstract}

\begin{abstract}
Preparation of composite magnets based on polymers with $\mathrm{SrFe}_{12} \mathrm{O}_{19}$ as filler have been conducted. Synthesis process was carried out by mixing powder of $\mathrm{SrFe}_{12} \mathrm{O}_{19}\left(\mathrm{SrM}, \mathrm{M}=\mathrm{Fe}_{2} \mathrm{O}_{3}\right)$ with epoxy and polyester polymer by ratio (in vol. fraction) of 30,40,50 and 60. The density of the sample was measured by Picno-meter method, where as the testing of mechanical properties was conducted with standard equipments of ASTM 412 and ISO R868 respectively. Microstructure and magnetic properties of the sample were measured by means of x-rays diffraction technique (XRD) and Vibrating Sample Magnetometer (VSM). The results showed that the highest density of the sample obtained about $3.3 \mathrm{gr} / \mathrm{ml}$ in SrM-epoxy composite with $50 \%$ content of SrM, where as highest tensile strength obtained about $297.23 \mathrm{~kg} / \mathrm{cm}^{2}$ from SrM-epoxy with $39 \%$ content of SrM. The highest magnetic remanence $\left(\mathrm{B}_{r}\right)$ and coercivity $\left(\mathrm{H}_{c}\right)$ was obtained of $\mathrm{B}_{r}=1.9 \mathrm{kGauss}$ and $\mathrm{H}_{c}=0.15$ kOe from SrM-polyester composite magnet with 50\% content of SrM. It can be concluded that composite SrMepoxy showed higher mechanical property than that of SrM-polyester composite. This shows that the epoxy polymer in composite magnetic materials which serves as a binder has a better property than polyester polymer for various filler content of SrM. But on the contrary, the nature of magnetism from a magnetic material of SrM-polyester composites is better than the SrM-epoxy.
\end{abstract}

KATA KUNCI: magnet composite, density, magnetic properties, tensile strength, hardness

\section{PENDAHULUAN}

Di Indonesia, banyak ditemui pemakaian magnet untuk berbagai macam keperluan baik untuk industri dalam skala besar maupun industri rumah tangga. Namun sayangnya, bahan magnet tidak bisa ditemukan begitu saja, melainkan harus dilakukan proses pengolahan terlebih dahulu agar bisa digunakan. Hal inilah yang menyebabkan negara kita mengimpor magnet dari luar negeri, sementara bahan baku yang merupakan sumber daya alam (SDA) lokal untuk membuat magnet

*E-MAIL: deswita@batan.go.id begitu melimpah di Indonesia.

Persoalan inilah yang mendorong untuk dikembangkannya penelitian yang bertujuan agar diperoleh magnet yang memenuhi sifat-sifat yang dikehendaki dan inovatif, sehingga dapat dengan mudah ditemukan di pasaran. Pembuatan magnet dari bahan campuran (komposit) ini merupakan salah satu usaha yang dilakukan agar dapat dikembangkan dewasa ini dengan baik di indonesia. Meskipun begitu, magnet yang dibuat harus memiliki kualitas yang baik agar dapat bermanfaat bagi msyarakat luas dan tentu saja dapat bersaing dengan negara-negara pembuat magnet lain.

Jumlah kebutuhan magnet untuk menunjang komunitas masyarakat modern saat ini sangatlah besar. Untuk keperluan rumah tangga misalnya, magnet digunakan sebagai holder, perangkat audio dan peralatan komunikasi maupun 
peralatan kantor seperti komponen komputer, printer, holder dan bahkan pemanfaatan kemagnetan sangat spektakuler adalah dalam proyek pembangkit energi dari fusi nuklir [1]. Berbeda dengan magnet hasil pengecoran atau magnet keramik, magnet komposit umumnya memiliki keunggulan sifat-sifat mekanik sesuai dengan rancangan pembuatannya dan lebih tahan terhadap korosi, karena tebungkus bahan polimer. Namun demikian sebagaimana magnet lainnya, sifat kemagnetan komposit juga diketahui berdasarkan kurva histerisis magnetiknya.

Untuk mendapatkan kurva histeresis suatu bahan magnet, pertama ditinjau cuplikan bahan ferromagnetik yang tidak termagnetisasi. Kemudian bahan tersebut diletakkan pada medan magnet luar, intensitasnya dinaikkan perlahan-lahan secara kontinyu, maka dapat dilakukan karakterisasi bahan tersebut dengan besaran-besaran yang ada [2, 3]. Bagian dari lengkungan kurva histerisis merupakan permeabilitas $(\mu)$, dimana pada intensitas medan maget, $\mathrm{H}$ adalah nol dan medan magnet menunjukkan harga tertentu yaitu $\mathrm{B}_{r}$ yang disebut remanensi. $\mathbf{B}_{r}$ merupakan nilai remanen magnet yang tersisa di dalam bahan setelah pengaruh medan magnet ditiadakan. Dan saat dimana medan magnet, B adalah berharga nol, sedang intensitas medan magnetik menunjukan harga tertentu yaitu $\mathrm{H}_{c}$ yang disebut dengan koersivitas bahan magnet. Nilai $\mathrm{H}_{c}$ ini menyatakan besar medan magnet balik yang di butuhkan guna menghilangkan kemagnetan suatu bahan. Untuk produk energi maksimum diperoleh dari hasil perkalian antara $\mathrm{B}_{r}$ dan $\mathrm{H}_{c}$ [4].

Dalam kegiatan ini, dibuat bonded magnet komposit dari bahan serbuk SrM yang berfungsi sebagai filler berbasis polimer epoksi dan poliester sebagai matrik. Tujuan dari kegiatan ini adalah untuk mempelajari sifat-sifat mekanik dan magnetik dari bahan magnet komposit SrM berbasis epoksi dan poliester yang dibuat dalam bentuk bonded magnet komposit serta mendapatkan informasi fakta-fakta yang mempengaruhinya.

\section{TATA KERJA}

Dalam kegiatan ini dipakai serbuk magnet stronsium heksaferit dengan rumus kimia $\mathrm{SrFe}_{12} \mathrm{O}_{19}$ atau $\mathrm{SrM}$ dengan $\mathrm{M}=$ $\mathrm{Fe}_{12} \mathrm{O}_{19}$ produk dari P.T. Sumimagne, Cilegon-Banten. Serbuk SrM berfungsi sebagai filler dan polimer sebagai matrik. Untuk membuat bahan magnet komposit SrM-polimer, disiapkan dua jenis polimer poliester dan epoksi beserta hardenernya yang dicampurkan dengan serbuk SrM. Perbandingan serbuk SrM dengan poliester dan epoksi masing-masing dibuat perbandingan dalam kadar SrM (dalam persen volume) yaitu 30, 40, 50 dan 60, kemudian sampel dicetak menggunakan cetakan. Sampel yang dihasilkan berupa lembaran magnet komposit dengan tebal kira-kira $2 \mathrm{~mm}$, panjang dan lebar masing-masing berukuran $15 \mathrm{~cm}$. Untuk kepentingan uji tarik, sampel dibuat berbentuk dumb bell dengan ukuran panjang $10 \mathrm{~cm}$, tebal $2 \mathrm{~mm}$ (lihat Gambar 1).

Sebelum dibuat sampel bahan komposit SrM-polimer, bahan dasar serbuk SrM dikarakterisasi menggunakan fasilitas XRD dan VSM yang ada di PTBIN - Batan. Densitas ba-

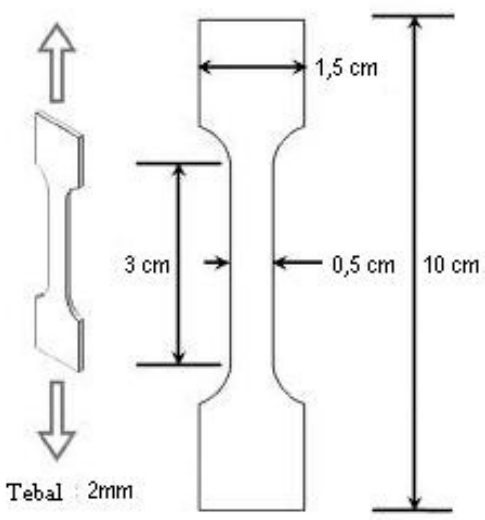

Gambar 1: Bentuk sampel uji tarik sesuai dengan standar ASTM D412-06ae2.

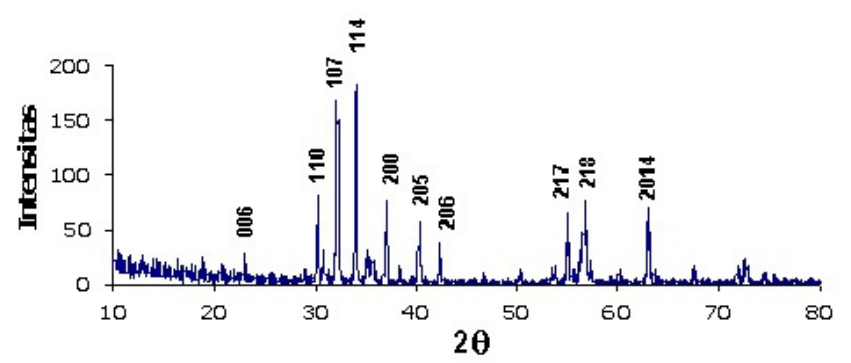

Gambar 2: Pola difraksi sinar-x dari serbuk SrM hasil dari PT. Sumimagnet - Banten.

han komposit diukur dengan metoda Pikno-meter, sedangkan pengujian sifat mekanik dilakukan dengan menggunakan peralatan standar ASTM D412-06ae2 dengan kecepatan tarik 50 $\mathrm{mm}$ /detik dan uji kekerasan dilakukan dengan menggunakan metoda Shore A (durometer) Merk Zwik sesuai dengan standar DIN 53505 dan ISO R868 dengan pembebanan seberat 1 $\mathrm{kg}$ [5-7]. Sifat kemagnetan (koersivitas dan remanensi) bahan komposit SrM-polimer diukur dengan Vibrating sampel Magnetometer (VSM) menggunakan medan luar \pm 1 Tesla.

\section{HASIL DAN PEMBAHASAN}

Mikrostruktur dan sifat kemagnetan dari bahan dasar filler SrM terlebih dahulu diuji kualitasnya menggunakan fasilitas XRD dan VSM yang ada di PTBIN, Batan. Pada Gambar 2 diperlihatkan pola difraksi sinar-x dari bahan SrM yang akan digunakan sebagai filler. Berdasarkan pada pola difraksi Gambar 2, tampak serbuk $\mathrm{Sr}$ heksaferit berfasa tunggal dengan struktur hexagonal magnetoplumbite dengan space group $\mathrm{P}$ 63/mmc [8].

Hasil uji kualitas sifat kemagnetan dari bahan serbuk filler SrM, yang diukur dengan VSM ditunjukkan dengan kurva histerisis pada Gambar 3. Dari data kurva histerisis pada Gambar 3 , diperoleh nilai koersivitas, $\mathrm{H}_{c}=1,8 \mathrm{kOe}$ dan remanensi, $\sigma_{r}$ $=38,2 \mathrm{emu} / \mathrm{gr}$. 


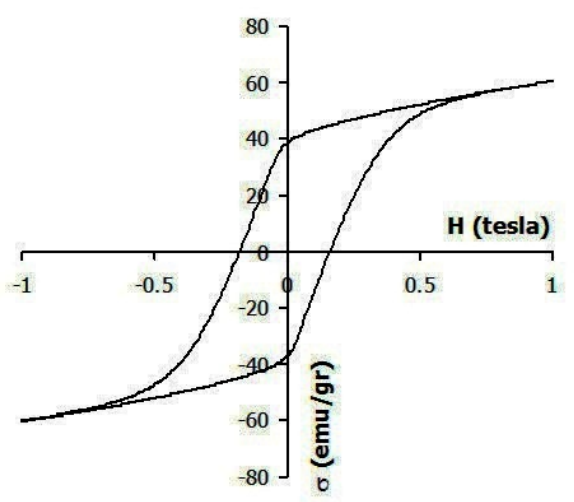

Gambar 3: Kurva histerisis serbuk magnet SrM hasil dari PT. Sumimagnet - Banten.

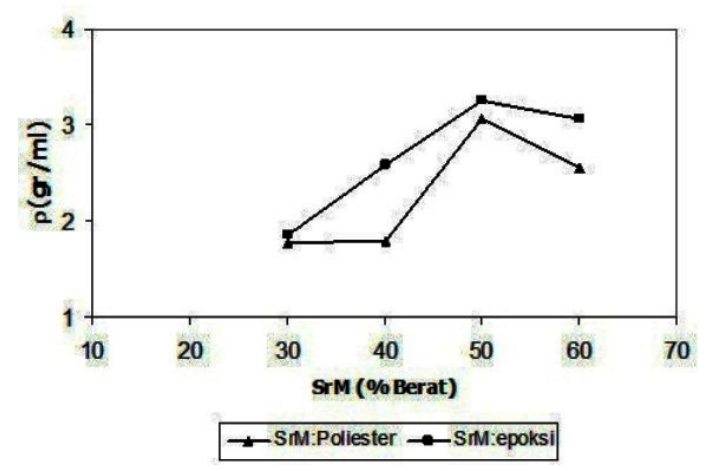

Gambar 4: Densitas rata-rata bahan komposit magnet SrM-Poliester dan SrM-epoksi hasil pengukuran dengan metoda Pikno-meter.

Metoda Pikno-meter merupakan metoda yang amat sederhana untuk mengukur densitas suatu bahan berdasarkan prinsip Archimedes [7, 9]. Hasil pengukuran densitas rata-rata bahan komposit SrM-poliester dan SrM-epoksi ditunjukkan pada Gambar 4. Berdasarkan pada data Gambar 4 terlihat bahwa densitas, $\rho$ baik komposit SrM-epoksi maupun SrMpoliester mengalami peningkatan sejalan dengan bertambahnya berat SrM hingga 50\%.

Densitas bahan komposit SrM-epoksi diperoleh sekitar 3,3 $\mathrm{gr} / \mathrm{ml}$ sedikit lebih besar bila dibandingkan dengan $\rho$ bahan komposit SrM-poliester yang hanya sekitar 3,0 gr/ml. Namun demikian, secara keseluruhan kedua bahan komposit SrM-polimer tersebut, memiliki $\rho$ nya lebih besar dari $\rho$ bahan murni baik polimer poliester maupun epoksi yang hanya memiliki $\rho$ sekitar 1,1 sampai $1,5 \mathrm{gr} / \mathrm{ml}$. Peningkatan nilai $\rho$ kedua bahan komposit tersebut berkaitan erat dengan penambahan filler $\operatorname{SrM}(\rho \approx 5,62 \mathrm{~g} / \mathrm{ml})$ dan membentuk menjadi bahan komposit.

Untuk mengetahui hubungan korelasi antara kekuatan tarik dengan nilai densitas, maka sampel diuji dengan peralatan uji tarik standar D412-06ae2. Sebelum dilakukan pengujian, sampel uji harus dipersiapkan berbentuk dumb bell (Gambar 1) berdasarkan standar sampel yang telah ditentukan [10].

Hasil uji kekuatan tarik, $\sigma$ sampel magnet komposit SrM berbasis poliester dan epoksi dengan berbagai kandungan $\mathrm{SrM}$

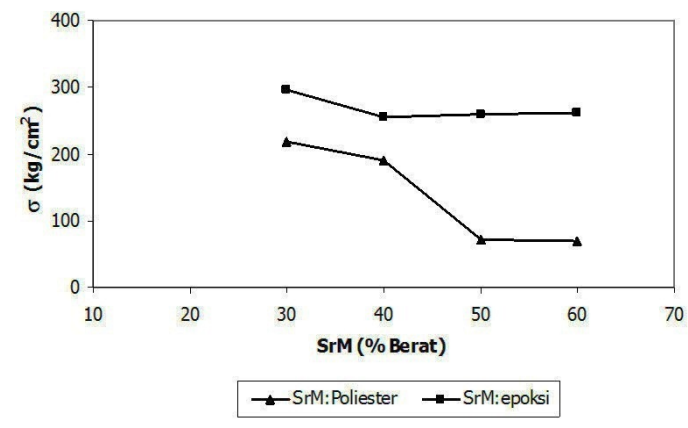

Gambar 5: Hasil uji kekuatan tarik, sampel komposit SrM:poliester dan SrM:epoksi dengan kadar SrM 30, 40, 50 dan 60\% berat.

dapat dilihat pada Gambar 5. Berdasarkan data kurva pada Gambar 5 terlihat bahwa secara keseluruhan magnet komposit SrM berbasis epoksi memiliki sifat mekanik lebih tinggi, bila dibandingkan dengan magnet komposit SrM poliester. Untuk magnet komposit SrM berbasis polimer, sifat mekanik yang diperoleh hanya mempunyai kekuatan tarik dan perpanjangan putus.

Kekuatan tarik komposit SrM-epoksi dan SrM-poliester cenderung turun dengan bertambahnya kadar SrM hingga $60 \%$. Kekuatan tarik optimum bahan komposit SrM-epoksi diperoleh dengan nilai $\sigma=297,23 \mathrm{~kg} / \mathrm{cm}^{2}$ dengan $30 \%$ kadar SrM. Sebaliknya, kekuatan terendah diperoleh dengan nilai $\sigma \approx 69,73 \mathrm{~kg} / \mathrm{cm}^{2}$ pada bahan komposit SrM-poliester. Dengan demikian, kekuatan optimum sifat mekanik bahan komposit SrM-epoksi diperoleh untuk 30\% kadar SrM dan $70 \%$ epoksi. Tingginya sifat mekanik komposit SrM-epoksi dibandingkan dengan komposit SrM-poliester disebabkan oleh dalam bentuk asli epoksi resin keras, kaku dan getas. Tetapi dalam penggunaan, hampir selalu mengandung bahan campuran lain untuk menyesuaikan sifat mekaniknya. Sifat mekanik sangat banyak dimodifikasi sifatnya, baik dari sisi kekuatan, kekenyalan, keuletan, sampai kearah sobekan lebih baik dari pada poliester bersifat lebih lunak, sehingga persen kadar filler yang sama tidak berpengaruh.

Sifat mekanik komposit sangat dipengaruhi oleh sifat fisik dan mekanik bahan penyusunnya. Karena dalam penelitian ini menggunakan matrik jenis poliester dan epoksi yang merupakan bahan polimer yang mempunyai deformasi elastik yang besar. Dimana jika bahan tersebut dikenai deformasi (gaya tarik), maka akan meningkatkan modulus elastiknya saja [2].

Untuk mendapatkan kekerasan secara makro, maka pada bahan komposit SrM-polimer dilakukan uji kekerasan Shore A. Uji ini menggunakan identer berbentuk jarum yang digerakkan oleh pegas terkalibrasi. Nilai identer Shore A menunjukkan kedalaman penetrasi yang dikenai pada permukaan bahan uji dan nilai ini juga yang dapat mengukur kompresi pegas oleh beban.

Dari data hasil pengukuran diperoleh nilai kekerasan dari kedua bahan komposit SrM-epoksi dan SrM-poiester, ditunjukkan pada Gambar 6. Nilai kekerasan tertinggi diperoleh dari bahan komposit SrM-epoksi dengan 98,3 Shore A dan lebih tinggi dari bahan komposit SrM-poliester untuk berbagai kadar SrM. Berdasarkan kurva pada Gambar 6, nilai 


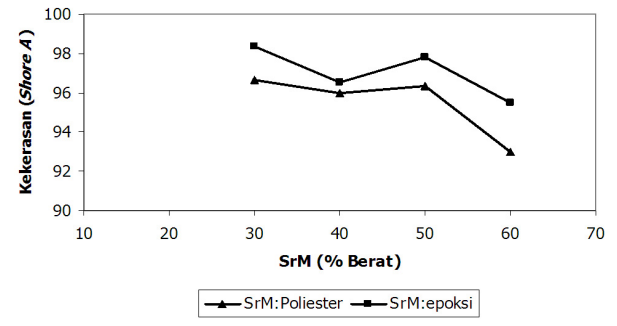

Gambar 6: Hasil uji kekerasan komposit SrM:poliester dan SrM:epoksi dengan kadar SrM 30, 40, 50 dan 60\%.
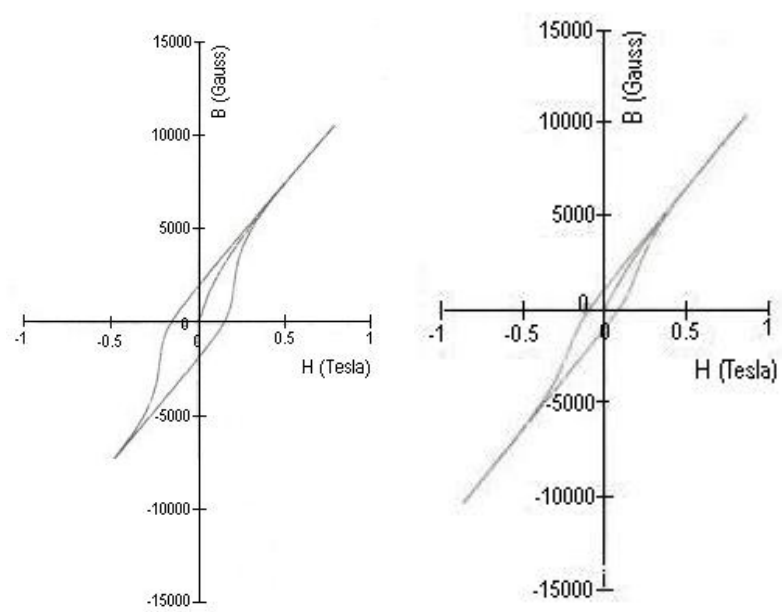

Gambar 7: Kurva histerisis magnet komposit a). SrM:poliester dan b). SrM:epoksi dengan kadar SrM 50\%.

kekerasan kedua bahan komposit SrM-polimer turun seiring dengan bertambahnya kadar SrM.

Kurva histeresis dari bahan magnet komposit SrM-epoksi dan SrM-poliester yang telah dimagnetisasi diukur dengan VSM ditunjukkan, seperti ditunjukkan pada Gambar 7. Dalam proses pengukuran dengan VSM, sampel yang diukur diletakkan dalam medan magnet luar $(\mathrm{H})$, kemudian intensitas magnetnya dinaikkan perlahan-lahan secara kontinyu. Saat dimana intensitas medan magnetik nol dan medan magnet menunjukkan harga tertentu yaitu $\mathrm{B}_{r}$ yang disebut rema- nensi. Untuk bahan magnet komposit SrM-poliester, diperoleh nilai magnet remanen, $\mathrm{B}_{r}=1956$ Gauss $(1,956 \mathrm{kG})$ dengan koersivitasnya, $\mathrm{H}_{c}=0,15 \mathrm{~T}$ ( $15 \mathrm{Oe}$ ) lebih besar bila dibandingkan dengan sifat kemagnetan bahan magnet komposit SrM-epoksi yang hanya menghasilkan nilai remanensi, $\mathrm{B}_{r}=1052$ Gauss $(1,052 \mathrm{kG})$ dan koersivitasnya, $\mathrm{H}_{c}=0,09 \mathrm{~T}$ (9 Oe). Dari kurva pada Gambar 7, terlihat bahwa besarnya kekuatan magnet di dalam bahan komposit SrM-poliester lebih tinggi dibandingkan dengan besarnya kekuatan magnet di dalam bahan magnet komposit SrM-epoksi, yang dicirikan oleh besarnya nilai remanensi, $\mathrm{B}_{r}$. Demikian pula besarnya koersivitas $\left(\mathrm{H}_{c}\right)$ atau medan magnet balik yang di butuhkan guna menghilangkan kemagnetan suatu bahan, untuk bahan komposit SrM-poliester lebih besar dari pada dalam bahan komposit SrM-epoksi.

TABEL I: Sifat magnetik bahan komposit SrM: poliester dan SrM:epoksi hasil pengukuran dengan VSM.

\begin{tabular}{ccccc}
\hline \hline No & Sampel & $\mathrm{B}_{r}(\mathrm{kG})$ & $\mathrm{H}_{c}(\mathrm{kOe})$ & $(\mathrm{BH})_{\text {maks }}(\mathrm{kGOe})$ \\
\hline 1. & SrM:poliester & 1,95 & 0,15 & 0,2940 \\
2. & SrM:epoksi & 1,05 & 0,09 & 0,0940 \\
\hline \hline
\end{tabular}

Nilai produk energi maksimum $(\mathrm{BH})_{\text {maks }}$ dari kurva Gambar 7 dapat diperoleh dari nilai maksimal hasil perkalian antara $\mathrm{B}_{r}$ dan $\mathrm{H}_{c}$ pada kuadran kedua kurva histeresis. Dari data kurva histerisis diperoleh nilai $(\mathrm{BH})_{\text {maks }}=0,2940 \mathrm{kGOe}$ untuk bahan magnet komposit SrM-poliester dan $(\mathrm{BH})_{\text {maks }}=$ 0,0945 kGOe untuk bahan magnet komposit SrM-epoksi.

\section{SIMPULAN}

Densitas dan sifat mekanik bahan komposit SrM-epoksi lebih tinggi dari pada densitas dan sifat mekanik bahan komposit SrM-poliester untuk berbagai kadar SrM. Ini menunjukkan bahwa untuk fungsi sebagai binder, bahan komposit SrM-epoksi lebih baik dari pada magnet komposit SrMpoliester. Namun sebaliknya, sifat kemagnetan baik koersivitas maupun remanesi bahan komposit SrM-poliester lebih unggul dibandingkan dengan bahan komposit SrM-epoksi.
[1] Ridwan, Magnet dan Kemagnetan: Dari Aplikasi Sederhana Hingga Fusi Nuklir, Orasi Pengukuhan Profesor Riset Bidang Fisika Zat Padat, Serpong 13 Desember 2010.

[2] http://ujangnugraha.blogspot.com/2010/01/makalah-materialteknik.html, diacu tanggal 18 Januari 2010.

[3] G. zhang, B. Li, Physics World, 21, 27-29 (2007).

[4] Rajca et al., Science, 294, 1503 (2001).

[5] Diharjo K. dan Nusi S.H., Studi Sifat Tarik Bahan Komposit Berpenguat Serat Rami Dengan Matrik Unsaturated Poliester, Prosiding Seminar Nasional, Teknik Mesin FT Univ. Petra Surabaya, 2006.

[6] Diharjo K., dkk., The Flexural and Impact Properties of Random and Woven kenaf Fiber Reinforced Polyester Composite, Proseding SNTTM-IV, Hotel Patra, UNUD, Bali, November 2005.

[7] Diharjo K., dkk., Tensile Properties Reinforced Polyester Composite, National Seminar Proceeding, Center of Inter University, UGM, Yogyakarta, Indonesia. 2005.

[8] JCPDS- International Center for Diffraction Data, PCPDF 430002.

[9] http://www.zaidan.blog.inair.ac.id/files/2009/09/03/rapatzat.pdf.

[10] H. Onggo dan A.H.D. Abdullah, Prosiding Seminar Nasional MAPEKI XI , 524 - 530 (2008). 